\title{
Antipsychotic treatment resistance in first-episode psychosis: prevalence, subtypes and predictors
}

\author{
A. Demjaha ${ }^{1 *}$, J. M. Lappin ${ }^{2}$ t, D. Stahl ${ }^{3}$, M. X. Patel ${ }^{1}$, J. H. MacCabe ${ }^{1}$, O. D. Howes ${ }^{1,4}$, M. Heslin $^{5}$, \\ U. A. Reininghauss ${ }^{1}$, K. Donoghue ${ }^{6}$, B. Lomas ${ }^{1}$, M. Charalambides ${ }^{1}$, A. Onyejiaka ${ }^{1}$, P. Fearon ${ }^{7}$, \\ P. Jones ${ }^{8}$, G. Doody ${ }^{9}$, C. Morgan ${ }^{1,10} \ddagger$, P. Dazzan ${ }^{1,2} \ddagger$ and R. M. Murray ${ }^{1} \ddagger$ \\ ${ }^{1}$ Institute of Psychiatry, Psychology and Neuroscience, King's College London, London, UK \\ ${ }^{2}$ School of Psychiatry, University of New South Wales, Sydney, NSW, Australia \\ ${ }^{3}$ Department of Biostatistics, Institute of Psychiatry, Psychology and Neuroscience, King's College London, London, UK \\ ${ }^{4}$ Psychiatric Imaging Group, Clinical Science Centre, Imperial College, London, UK \\ ${ }^{5}$ Health Service and Population Research Department, Institute of Psychiatry, Psychology and Neuroscience, King's College London, London, UK \\ ${ }^{6}$ Addictions Department, Institute of Psychiatry, Psychology and Neuroscience, King's College London, London, UK \\ ${ }^{7}$ Department of Psychiatry, Trinity College, Dublin, Republic of Ireland \\ ${ }^{8}$ Department of Psychiatry, University of Cambridge, Cambridge, UK \\ ${ }^{9}$ Division of Psychiatry, University of Nottingham, Nottingham, UK \\ ${ }^{10}$ Health Service and Population Research Department, Centre for Epidemiology and Public Health, Institute of Psychiatry, King's College London, \\ London, UK
}

Background. We examined longitudinally the course and predictors of treatment resistance in a large cohort of firstepisode psychosis (FEP) patients from initiation of antipsychotic treatment. We hypothesized that antipsychotic treatment resistance is: (a) present at illness onset; and $(b)$ differentially associated with clinical and demographic factors.

Method. The study sample comprised 323 FEP patients who were studied at first contact and at 10-year follow-up. We collated clinical information on severity of symptoms, antipsychotic medication and treatment adherence during the follow-up period to determine the presence, course and predictors of treatment resistance.

Results. From the $23 \%$ of the patients, who were treatment resistant, $84 \%$ were treatment resistant from illness onset. Multivariable regression analysis revealed that diagnosis of schizophrenia, negative symptoms, younger age at onset, and longer duration of untreated psychosis predicted treatment resistance from illness onset.

Conclusions. The striking majority of treatment-resistant patients do not respond to first-line antipsychotic treatment even at time of FEP. Clinicians must be alert to this subgroup of patients and consider clozapine treatment as early as possible during the first presentation of psychosis.

Received 9 December 2016; Revised 26 January 2017; Accepted 27 January 2017; First published online 11 April 2017

Key words: Schizophrenia, First-Episode- Psychosis, Treatment-Response, Clozapine, Treatment-Resistant.

\section{Introduction}

It is widely established that treatment response in schizophrenia is heterogeneous (Lieberman et al. 1993; Levine et al. 2012); whilst a good number of patients achieve remission, a considerable proportion remains actively and persistently psychotic despite optimal pharmacological treatment. It remains, however, unknown whether these patients are treatment resistant from the illness onset (TRO), or whether

\footnotetext{
* Address for correspondence: A. Demjaha, Ph.D., Institute of Psychiatry, Psychology and Neuroscience, King's College London, 16 De Crespigny Park, London SE5 8AF, UK.

(Email: arsime.demjaha@kcl.ac.uk)

+ Joint first author.

$\ddagger$ Joint senior author.
}

they gradually become resistant as illness progresses in the context of multiple episodes, chronic exposure to medication or neurochemical sensitization. We have previously demonstrated that dopamine dysfunction is not evident in treatment-resistant patients (Demjaha et al. 2012, 2014) and this, together with the evidence linking various underlying neurodevelopmental factors to treatment resistance (McCreadie et al. 1989; Robinson et al. 1999), may suggest that in this distinct subgroup, dopamine-blocking antipsychotics are ineffective right from the beginning of illness. In support of this, first-episode psychosis (FEP) studies have established that even during the first episode of illness where treatment response to antipsychotic medication tends to be greater; up to one-quarter of patients continue to have persistent symptoms despite adequate treatment (Lieberman et al. 1993; Agid et al.

This is an Open Access article, distributed under the terms of the Creative Commons Attribution licence (http://creativecommons.org/licenses/by/4.0/), which permits unrestricted re-use, distribution, and reproduction in any medium, provided the original work is properly cited. 
2011; Schennach et al. 2012). Furthermore, an earlier study of patients with chronic illness has documented that the majority of 'poor responders' were unresponsive throughout their illness (Kolakowska et al. 1985). Other authors, however, have claimed that treatment resistance evolves in the context of a long duration of untreated psychosis (DUP) or multiple episodes of illness, suggesting that psychotic episodes have a neurotoxic effect, which gave support to the 'neurodegeneration hypothesis' of antipsychotic treatment resistance (Loebel et al. 1992).

With respect to predictors of treatment resistance, the literature to date remains sparse and inconsistent. Although greater severity of negative symptoms, younger age at onset, poor pre-morbid functioning, male gender and a longer DUP have all been linked to treatment resistance (McCreadie et al. 1989; Lieberman et al. 1993; Robinson et al. 1999), these studies have mostly focused on poor outcome or poor response to antipsychotic treatment, and have not distinguished between different subtypes of treatment resistance, which may account for disparity in results.

Identifying whether and which patients are likely to be TRO is of fundamental clinical importance, particularly with regards to introducing as early as possible the only antipsychotic effective in these patients (Kane et al. 1988). Thus, we examined the course of treatment resistance over a 10-year period, in a large cohort of FEP patients. Additionally, we investigated predictors of treatment resistance including gender, mode of onset, ethnicity, DUP and negative symptoms, exclusively in those patients who were resistant to antipsychotic treatment from the illness onset. Based on evidence to date, we hypothesized that antipsychotic treatment resistance is: (a) present at illness onset; and (b) differentially associated with clinical and demographic factors.

\section{Method}

\section{Study sample}

Data originate from AESOP-10, a 10-year longitudinal, population-based study of incident cases of psychosis from defined catchment areas. At baseline, all patients aged 16-64 years who presented with FEP over a 2-year period in centres in southeast London and Nottingham (UK) were invited to take part at approximately 10 years post-inclusion. Ethical approvals for both the baseline and follow-up studies were obtained from the local research ethics committees. At baseline, patients gave consent to be re-contacted for follow-up.

The analytic sample comprised 323 patients for whom there was complete information on medication, adherence to treatment and symptom ratings over the 10-year follow-up period (Fig. 1). A comparison of cases with adequate treatment information $(n=323)$ and those without complete information $(n=163)$ did not reveal any notable differences in age, age of onset, gender, ethnicity, diagnosis, mode of onset, DUP or negative symptoms. Similarly, there were no statistically significant differences in these parameters between cases with adequate treatment information $(n=323)$ and the rest of the total sample including 71 cases lost to follow-up $(n=234)$.

\section{Baseline clinical assessment}

Psychopathology was assessed at first contact with psychiatric services using the Schedules for Clinical Assessment in Neuropsychiatry (SCAN; World Health Organization, 1994). Diagnoses were established according to International Classification of Diseases (ICD)-10 diagnostic criteria for research (World Health Organization, 1992) during clinical consensus meetings. There was $80 \%$ inter-rater agreement on diagnostic category.

Using factor analysis, baseline symptoms were categorized into five psychopathological dimensions (manic, reality distortion, negative, depressive and disorganized) (Demjaha et al. 2009). Age at onset was established as the age at which first psychotic symptoms appeared. Mode of onset was rated, using the World Health Organization (WHO) Personal and Psychiatric History Schedule, according to two categories: acute (psychotic symptoms appeared incrementally within 1 month); and insidious (psychotic symptoms appeared incrementally over a period of more than 1 month). DUP was defined as the period in weeks from the onset of psychosis to first contact with statutory mental health services.

\section{Follow-up clinical assessments}

Length of follow-up was defined as the period between first presentation to psychiatric services and date of follow-up assessment. Clinical information was obtained through subject interview, case-note review and informant interview, and recorded using the WHO Life Chart, which was adapted to include additional information on service contacts and antipsychotic treatment (Harrison et al. 2001; Morgan et al. 2014). Mental state was assessed with the SCAN.

Case histories were reconstructed over the follow-up period to complete the Life Chart. This involved close examination of medication charts, medical records and clinical documentation. The start and end dates of all prescribed antipsychotic medication, dosage, adherence to treatment, and the reason for change or termination, were recorded. 


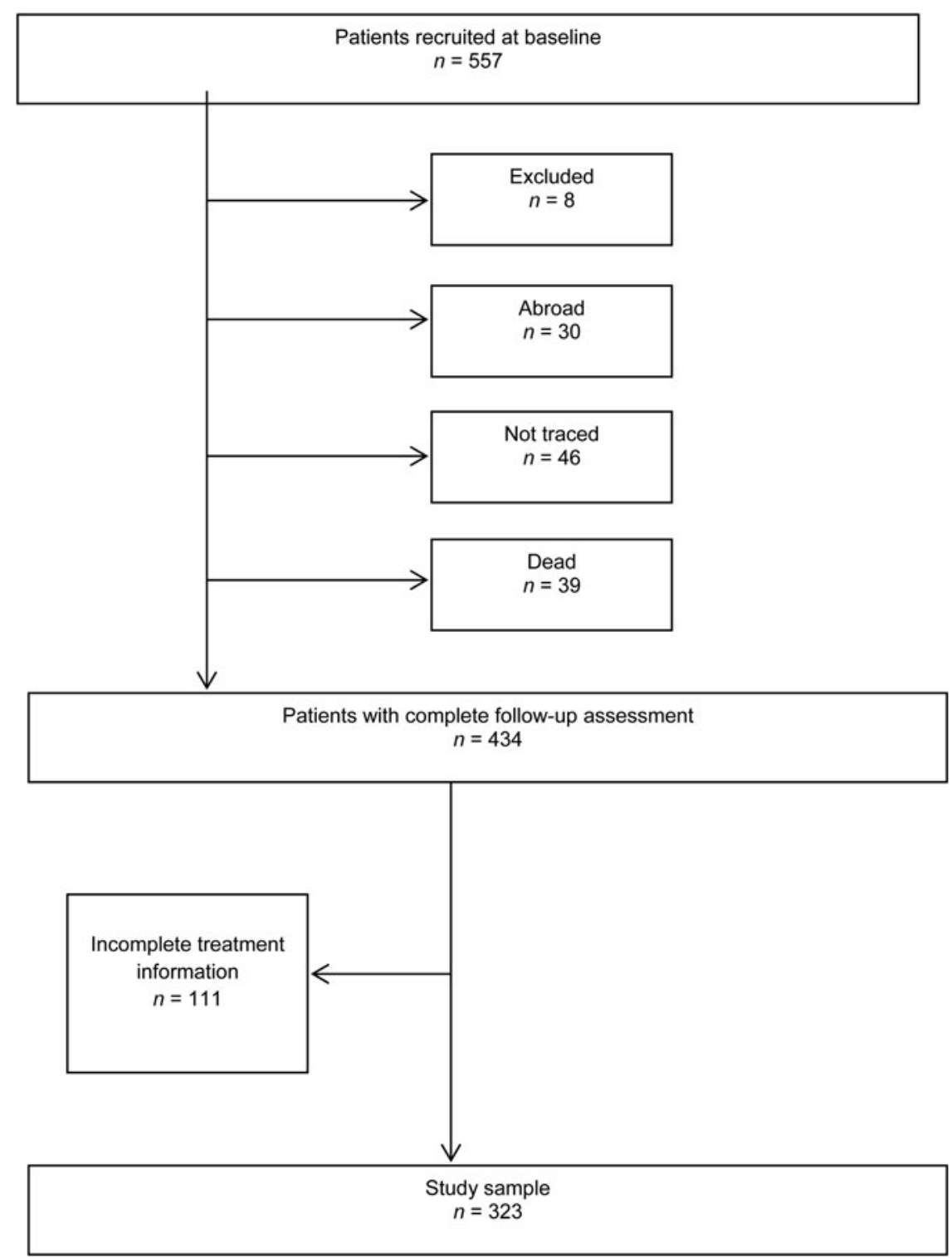

Fig. 1. Study sample derived from the ÆSOP-10. There were no statistically significant differences (at $p<0.05)$ in terms of gender, ethnicity, study centre, duration of untreated psychosis (DUP) or diagnosis between subjects initially recruited $(n=557)$ and those with complete follow-up assessment $(n=412)$. The subjects with complete $(n=323)$ and incomplete treatment information $(n=234)$ did not differ significantly in terms of gender, ethnicity, DUP or diagnosis; however, there were significant differences in study centre $(p=0.002)$.

In line with National Institute for Health and Care Excellence (NICE) (National Institute for Health and Care Excellence, 2014) criteria, patients who had received two sequential antipsychotic trials, each of at least 4 weeks' duration at a daily dose of 400-600 $\mathrm{mg}$ of chlorpromazine equivalents, but continued to have persistent psychotic symptoms, which was defined as having a rating of at least moderate severity on one or more positive symptoms as rated by SCAN, and despite recorded adherence to medication, were classified as 'treatment resistant'.

Patients were classified as TRO if they met criteria for treatment resistance following the first two trials of antipsychotic medication. Patients with 'delayed-onset treatment resistance' (DOTR) were defined as those who, following initial response to treatment, subsequently met criteria for treatment resistance.

Treatment response was defined as a state, of at least 6 months' duration, in which no symptoms or only symptoms of mild severity, not interfering with daily functioning, were experienced (Andreasen et al. 2005).

\section{Statistical analysis}

Analyses were performed using SPSS (version 22.0; SPSS Inc., USA) and R 3.1 (R Core Team, 2014). 
Descriptive data are reported as frequencies and percentages or means and standard deviations as appropriate. Demographic and clinical characteristics were compared between subjects with complete and incomplete clinical information using $\chi^{2}$, Fisher's exact or independent-samples $t$ tests as appropriate.

\section{Regression analyses}

First step. To investigate the predictors of TRO we performed univariable logistic regressions for predictor variables and the main outcome 'TRO'. Based on evidence to date we have included the following predictors: age at onset, gender, ethnicity, diagnoses, DUP, mode of onset and negative symptom dimension derived by factor analysis of baseline symptoms rated by SCAN. Odds ratios (ORs) and 95\% confidence intervals are reported (see Table 2).

Second step. We performed multivariable analyses to describe the relationship between ('treatment resistance') TRO and clinical and demographic variables, controlling for gender, age of onset and type of diagnosis, to identify the best set of predictors. However, since our sample size and the observed number of TRO patients relative to the number of predictors in the final data were relatively modest, the subset model selection procedures would violate every principle of statistical estimation and hypotheses testing. Thus, we penalized logistic regression to obtain stable parameters and improve prediction accuracy (Harrell, 2015). The LASSO regression approach was used which penalized the sum of the absolute values of the regression coefficients and thus shrank regression coefficients towards 0 . The shrinkage penalty $\lambda$ was chosen by a repeated 10-fold cross-validation method (Hastie et al. 2009) and implemented in the $R$ package glmnet.

\section{Model performance}

Penalized regression methods do not provide standard errors or other inferential statistics. We assessed the predictive performance of the final penalized logistic regression model using the Brier score and percentage explained deviance (or McFadden's pseudo $R^{2}$ ) as measures of the overall prediction accuracy.

\section{Correction for optimism}

We used the same dataset to fit the model and to assess its predictive ability and validated our model by following recommendations by Harrell (2015) to correct for optimisms of our estimates using bootstrapping procedures. This estimate of optimism is then subtracted off the naive estimate of regression parameter estimates, Brier score and McFadden pseudo $R^{2}$ of our model.

\section{Results}

Rigorous examination of clinical information including the medication data, severity of symptoms and information on adherence to treatment recorded over a 10-year period revealed that 74 patients $(23 \%)$ met criteria for treatment resistance. The majority of these patients $(n=$ $62 / 74 ; 84 \%$ ), were TRO, as they had not responded to antipsychotic medication from the initiation of treatment; 212 (66\%) met criteria for treatment response (responders). The remaining 37 (11\%) had never received an adequate trial of antipsychotic medication and therefore could not be included in either category (unclassified; UC).

The 286 subjects that could be classified according to response (i.e. meeting response criteria) and those with incomplete information, comprising in addition $37 \mathrm{UC}$ (total $n=271$ ) did not differ in any of these parameters. Clinical and demographic characteristics of the analytic sample are presented in Table 1.

Qualitative exploration revealed that patients with DOTR had a later age at onset by approximately 4 years than TRO patients [mean age: 28.3 (S.D. $=12.2$ ) v. 24.8 (S.D. =6.3) years, respectively]. All DOTR patients had a diagnosis of schizophrenia, and most $(n=9,75 \%)$ had received clozapine. They developed treatment resistance on average 5 years after initial treatment, and after an average of four admissions (range 1-19).

Of the patients in the treatment-resistant group, 50 received clozapine; we identified 12 as clozapine treatment resistant (CTR), and 14 patients as clozapine responders. Patients were considered CTR if they had persistent symptoms of at least moderate severity despite complying with clozapine treatment for at least 6 months (Meltzer, 1997) at a daily dose of at least $400 \mathrm{mg}$. More than a third $(n=18)$ could not be included in either group as they had received a suboptimal trial of clozapine. For the remaining six patients, sufficient clinical and response data to determine response were lacking. Almost all CTR patients were men $(n=11)$, all had a diagnosis of schizophrenia $(n=12)$, and they had very similar age at onset compared with clozapine responders [mean age: 24.2 (S.D. $=6.8$ ) v. 24.3 (S.D. $=7.5$ ) years, respectively]. CTR patients received on average $700 \mathrm{mg}$ of clozapine daily.

\section{Predictors of TRO}

\section{Univariable logistic regressions}

The odds of developing TRO were higher among those with diagnosis of schizophrenia, earlier onset of psychosis, higher scores on negative symptoms, insidious 
Table 1. Clinical and demographic characteristics of the analytic sample

\begin{tabular}{|c|c|c|c|c|}
\hline & Responders $(n=212)$ & $\operatorname{TR}(n=74)$ & TRO $(n=62)$ & DOTR $(n=12)$ \\
\hline Mean age of onset, years (s.D.) & $30.1(10.5)$ & $25.4(7.7)$ & $24.8(6.3)$ & $28.3(12.2)$ \\
\hline \multicolumn{5}{|l|}{ Gender } \\
\hline Male & $114(53.8)$ & $53(71.6)$ & $44(71.0)$ & $9(75.0)$ \\
\hline Female & $98(46.2)$ & $21(28.4)$ & $18(29.0)$ & $3(25.0)$ \\
\hline \multicolumn{5}{|l|}{ Ethnicity } \\
\hline White British & $91(42.9)$ & $31(41.9)$ & $26(41.9)$ & $5(41.7)$ \\
\hline Black Caribbean & $56(26.4)$ & $22(29.7)$ & $19(30.6)$ & $3(25.0)$ \\
\hline Black African & $24(11.3)$ & $12(16.2)$ & $10(16.1)$ & $2(16.7)$ \\
\hline White other & $13(6.1)$ & $3(4.1)$ & $2(3.2)$ & $1(8.3)$ \\
\hline Asian & $17(8.0)$ & $3(4.1)$ & $3(4.8)$ & $0(0.0)$ \\
\hline Other & $11(5.2)$ & $3(4.1)$ & $2(3.9)$ & $1(8.3)$ \\
\hline \multicolumn{5}{|l|}{ Mode of onset } \\
\hline Acute & $97(45.8)$ & $25(33.8)$ & $17(27.4)$ & $8(66.7)$ \\
\hline Insidious & $87(41.0)$ & $36(48.6)$ & $33(53.2)$ & $3(25.0)$ \\
\hline Unknown & $28(13.2)$ & $13(17.6)$ & $12(21.4)$ & $1(8.3)$ \\
\hline \multicolumn{5}{|l|}{ Diagnosis } \\
\hline Schizophrenia & $140(66.0)$ & $70(94.6)$ & $58(93.5)$ & $12(100)$ \\
\hline Manic & $39(18.4)$ & $2(2.7)$ & $2(3.2)$ & $0(0.0)$ \\
\hline Depressive & $33(15.6)$ & $2(2.7)$ & $2(3.2)$ & $0(0.0)$ \\
\hline \multicolumn{5}{|l|}{ Education } \\
\hline Any qualification & $149(70.3)$ & $44(60.5)$ & $35(57.5)$ & $9(75.0)$ \\
\hline No qualification & $56(26.4)$ & $24(32.4)$ & $21(33.9)$ & $3(25.0)$ \\
\hline Unknown & $7(3.3)$ & $6(8.1)$ & $6(9.7)$ & \\
\hline Median DUP, weeks (interquartile range) & $5.7(2.0-22.8)$ & $23.8(4.4-101.1)$ & $26.3(4.4-104.3)$ & $11.5(4.6-32)$ \\
\hline Mean length of follow-up period, years (S.D.) & $9.8(2.12)$ & $9.3(2.21)$ & $9.6(2.31)$ & $10.9(1.04)$ \\
\hline
\end{tabular}

Data are given as number of participants (percentage) unless otherwise indicated.

TR, Treatment resistant; TRO, treatment resistant from onset; DOTR, delayed-onset treatment resistant; S.D., standard deviation; DUP, duration of untreated psychosis.

mode of onset and longer DUP. Furthermore, women were less likely to be treatment resistant. No effect of ethnicity was detected. For details, see Table 2.

The effect was strongest for negative symptoms (OR $1.24, p=0.003)$; the odds from being TRO for a patient presenting with four negative symptoms were 2.36 higher, and for a person with nine symptoms 6.9 times higher, compared with a patient with no negative symptoms.

\section{Multivariable LASSO regression (Table 3)}

The multivariable penalized LASSO regression with all variables included as potential predictors revealed that only diagnosis, younger age of onset, negative symptoms and longer DUP remained in the final model. The optimism corrected OR for negative symptoms was 1.088 . Thus, the predicted odds of treatment resistance were 1.4 higher for a patient with four negative symptoms and 2.13 higher for a patient with nine negative symptoms, compared with a patient with no negative symptoms after controlling for mode of onset, type of diagnosis, age of onset and DUP. Similarly, the final optimism corrected model explained $10.0 \%$ of the deviance and the Brier score was 0.146 , suggesting a moderate explanatory power.

\section{UC patients}

In all, 37 patients could not be classified according to their drug response; of these, 20 received only one antipsychotic during the course of their illness, and the remaining 17 received two or more antipsychotics at the sub-therapeutic dose. The majority of these patients had a diagnosis of schizophrenia $(n=30)$, and were male $(n=20)$. This group had a later age at onset by approximately 7 years than TRO patients [mean age: 0.31 .5 (s.D. $=11.4)$ v. 24.8 (s.D. $=6.3$ ) years, respectively].

\section{Discussion}

To our knowledge this is the first and the largest longitudinal FEP study to investigate the course and predictors of TRO. We demonstrated that the great majority of treatment-resistant patients did not achieve symptomatic 
Table 2. Univariable logistic regression predicting the effect of demographic and clinical factors on treatment resistance

\begin{tabular}{|c|c|c|c|}
\hline Variable & OR $(95 \% \mathrm{CI})$ & $p$ & $n$ \\
\hline \multicolumn{4}{|l|}{ Gender } \\
\hline Male & 1 & & \\
\hline Female & $0.48(0.25-0.86)$ & 0.014 & 274 \\
\hline Diagnosis & $\chi_{271}^{2}=22.24, p<0.0001$ & & 274 \\
\hline Schizophrenia & 1 & & \\
\hline Manic psychosis & $0.12(0.02-0.42)$ & 0.005 & \\
\hline Depressive psychosis & $0.15(0.02-0.5)$ & 0.01 & \\
\hline Age of onset & $0.93(0.89-0.97)$ & $<0.0001$ & 266 \\
\hline Negative symptoms & $1.24(1.08-1.42)$ & 0.003 & 239 \\
\hline \multicolumn{4}{|l|}{ Mode of onset } \\
\hline Acute & 1 & & 240 \\
\hline Insidious & $0.13(1.44-0)$ & 0.018 & \\
\hline Ethnicity & $\chi_{2}^{2}=0.73, p=0.69$ & & 274 \\
\hline White & 1 & & \\
\hline Black & $1.29(0.72-2.31)$ & 0.4 & \\
\hline Asian & $1.05(0.23-3.64)$ & 0.94 & \\
\hline \multicolumn{4}{|l|}{ Ethnicity (two categories) } \\
\hline White & 1 & & \\
\hline Non-white & $1.26(0.72-2.24)$ & 0.42 & \\
\hline DUP & $1.004(1.001-1.006)$ & 0.002 & 265 \\
\hline
\end{tabular}

OR, Odds ratio; CI, confidence interval; DUP, duration of untreated psychosis.

remission following first two trials of antipsychotic treatment.

\section{Heterogeneity of treatment resistance}

Our finding that over $80 \%$ of treatment-resistant patients have never shown response to antipsychotic treatment despite adequate adherence suggests that treatment resistance may be an enduring trait in these patients. This finding has recently been replicated in a subsequent study that found $70 \%$ of treatment-resistant patients to be resistant from FEP (Lally et al. 2016) and in addition is consistent with results from a FEP follow-up trial that documented that over $8 \%$ of patients did not respond to medication and were 'never well enough to be discharged' (MacMillan et al. 1986). Furthermore, Loebel et al. (1992), in their 3-year follow-up FEP study, documented that between 5 and $25 \%$ of their patients had persistent positive symptoms during the initial illness phase. Similarly, Agid et al. (2011) concluded that $80 \%$ of patients had treatment-resistant schizophrenia from illness onset, which largely corroborates our results. The finding that the majority of treatmentresistant patients do not respond from illness onset has direct clinical relevance; these are the patients that should be commenced on clozapine at the earliest possibility, particularly in light of the clozapine underutilization identified in a recent national audit (Patel et al. 2014), and evidence that the chances of responding to clozapine are higher if it is introduced earlier in their illness (Kane et al. 1988).

Notwithstanding the fact that a high percentage of patients are TRO, still a small, but not negligible, proportion of patients developed resistance to treatment later in the illness. Thus, there may well be one form of treatment resistance that manifests at the onset and another that develops during the course of the disorder, as previously advocated in the treatment resistance literature (Meltzer, 1997; Sheitman \& Lieberman, 1998). Whether the development of treatment resistance is due to the effect of repeated exposure to medication, dopamine sensitization, effects of neurodegeneration, or a combination of these factors remains to be answered. There is, however, some evidence from animal studies that chronic treatment with dopamineblocking antipsychotics induces dopamine receptor up-regulation, which could then reduce the efficacy of antipsychotic treatment and lead to breakthrough dopamine super-sensitivity. This could predispose some patients to becoming treatment resistant following repeated and chronic exposure to antipsychotic treatment, which warrants future investigations in larger samples.

Although our study did not identify patients whose response to medication improved during the course of illness, there is evidence for a third group of treatment-resistant patients who may achieve 
Table 3. Multivariable LASSO logistic regression predicting the effect of demographic and clinical factors on treatment resistance ${ }^{\text {a }}$

\begin{tabular}{lll}
\hline Variable & B & Odds ratio \\
\hline Intercept & -0.74 & \\
Gender & & \\
$\quad$ Male & N.A. & \\
Female & N.A. & \\
Diagnosis & & \\
$\quad$ Schizophrenia & 0 & 1 \\
Manic psychosis & -0.90 & 0.41 \\
Depressive psychosis & -0.65 & 0.52 \\
Age of onset & -0.029 & 0.97 \\
$\quad$ Negative symptoms & 0.085 & 1.088 \\
Mode of onset & & \\
Acute & 0 & 1 \\
Insidious & 0.247 & 1.28 \\
Ethnicity & & \\
$\quad$ White & - & \\
Non-white & - & 1.0013 \\
DUP & 0.0013 & \\
\hline
\end{tabular}

N.A., Not applicable; DUP, duration of untreated psychosis.

${ }^{\text {a }}$ Regression coefficients (for prediction models) and odds ratios corrected for optimism using the method according to Harrell (2015). Due to the small sample size of Asians, ethnicity was collapsed into white and non-white groups.

spontaneous remission or start responding to treatment later in life (Meltzer, 1997). This is in line with observations that older patients with schizophrenia require much less intensive maintenance antipsychotic treatment than their younger counterparts and could perhaps be explained by the fact that the dopamine system is age dependent, with significant reductions in dopaminergic transmission in older subjects being observed (Dreher et al. 2008). The fact that the mean age in our study is 30.5 years could explain the negative finding.

Finally, $11 \%$ of our sample had never received an adequate trial of antipsychotic medication. It has been advocated that patients at initial stages of their illness tend to respond to a lower dose of medication (Gardner et al. 2010), with published guidelines for medication response in FEP recommending a lower threshold of $300 \mathrm{mg}$ chlorpromazine equivalents (Buchanan et al. 2010). Therefore UC patients could have been classified as a responder at lower than threshold dosage. However, all our 37 UC cases have been persistently symptomatic; therefore we could not classify them as responders. On the other hand, had they received another antipsychotic, or higher dose of existing medication, some may have well responded to medication, but the reasons for inadequate treatment in this group remain unknown and warrant future exploration.

\section{Predictors of TRO}

Both negative symptoms and age at onset have been linked to treatment resistance (Kolakowska et al. 1985; McCreadie et al. 1989; Meltzer et al. 1997; Robinson et al. 1999). Contrary to our expectations, the study by Lally et al. (2016) did not find association with negative symptoms, which could be due to the fact that they used the Positive and Negative Syndrome Scale (PANSS) negative subscale that does not incorporate all negative symptoms such as motor retardation and active social avoidance.

Treatment resistance definitions to date have largely focused on persistent positive symptoms. In view of the negative symptom significance for treatment resistance, consideration should be given to their inclusion to determine treatment resistance. The Treatment Response and Resistance in Psychosis (TRRIP) Working Group has recently recommended the use of sub-specific 'negative' and 'cognitive' domains in addition to 'positive' domain when defining treatment resistance (Howes et al. 2016).

The finding that treatment-resistant patients are more likely to be younger at onset and have more negative symptoms adds some weight to the notion of the neurodevelopmental aetiology of treatment resistance, whereby disruptions during neurodevelopment may affect pathophysiology even before the psychotic symptoms manifest. Our finding that longer DUP predicts treatment resistance is in line with evidence from a comprehensive systematic review that documented the association between longer DUP and poor outcome (Marshall et al. 2005).

\section{Methodological considerations}

Data on medication, compliance and psychopathology collected over the follow-up period could have been affected by information bias. However, the WHO Life Chart is considered a reliable instrument for follow-up studies (Susser et al. 2000). In terms of symptomatology, there may be an overestimation of response, since patients who do not show significant behavioural disturbance may be rated by clinicians as 'stable', even when they are still symptomatic (Kolakowska et al. 1985).

We suggest that TRO may be neurodevelopmental in origin, in light of its association with negative symptoms and younger age at onset, but acknowledge that a small number of neurodevelopmental factors were evaluated. Thus, this is preliminary evidence that needs to be tested in future studies. Further, we advocate early use of clozapine, but in view of its adverse effects, it is essential that non-response to first-line 
antipsychotics is firmly established and our results are replicated and extended in studies that test larger number of treatment resistance predictors.

We further acknowledge that due to the small number of DOTR patients, only qualitative explorations were possible. This important group needs further evaluation in larger multicentre studies.

It has been suggested that time to response may vary between FEP and chronic patients with schizophrenia; there is some evidence that most FEP patients respond between weeks 8 and 16 of treatment with a single antipsychotic medication (Gallego et al. 2011). In our study, however, all TRO were persistently symptomatic throughout the follow-up period, and most have been on a single antipsychotic for longer than 18 weeks.

Another limitation relates to the treatment adherence measurements. The blood levels were not performed routinely for these patients, so we could not be certain of ensured compliance other than in cases, where depot medication was prescribed. However, we have only included patients for whom we had recorded data on adequate adherence collated from medication charts, medical records and clinical documentation

Finally, LASSO regression needs a complete case dataset. The sample size thus in our analysis has been reduced by $20 \%$. However, pairwise comparison of patients with complete and incomplete datasets did not reveal any significant differences for any demographic or clinical variables.

Nevertheless, we have examined prospectively, during the most critical phase of illness, the course and subtypes of treatment resistance in a large and relatively homogeneous sample of FEP patients, who were free of the effects of prior antipsychotic treatment and yielded results of theoretical and clinical importance.

\section{Conclusion}

Our data indicate that the great majority of treatmentresistant patients are resistant from illness onset. We believe that this form of treatment resistance is a stable phenotype of illness marked by more severe negative symptoms and younger age at onset. Our findings will hopefully alert clinicians to the surprisingly high prevalence of treatment resistance at the initial presentation of psychosis, and assist with early detection of patients who are most likely not to respond to dopaminergic blockade. This has important implications for treatment paradigms in FEP, particularly with regards to introducing clozapine as early as possible following first presentation with the aim of preventing years of enduring treatment resistance and increasing functional disability. However, in view of adverse side effects of clozapine, future studies need to replicate our findings in larger treatment-resistant samples and examine all relevant predictors in order to detect accurately patients who are likely to be at risk of not responding to treatment.

\section{Acknowledgements}

This study was supported by successive Medical Research Council grants.

\section{Declaration of Interest}

There are no potential conflicts of interest with respect to the research, authorship and/or publication of this article.

\section{References}

Agid O, Arenovich T, Sajeev G, Zipursky RB, Kapur S, Foussias G, Remington G (2011). An algorithm-based approach to first-episode schizophrenia: response rates over 3 prospective antipsychotic trials with a retrospective data analysis. Journal of Clinical Psychiatry 72, 1439-1444.

Andreasen NC, Carpenter WT, Kane JM, Lasser RA, Marder SR, Weinberger DR (2005). Remission in schizophrenia: proposed criteria and rationale for consensus. American Journal of Psychiatry 162, 441-449.

Buchanan RW, Kreyenbuhl J, Kelly DL, Noel JM, Boggs DL, Fischer BA, Himelhoch S, Fang B, Peterson E, Aquino PR, Keller W (2010). The 2009 schizophrenia PORT psychopharmacological treatment recommendations and summary statements. Schizophrenia Bulletin 36, 71-93.

Demjaha A, Egerton A, Murray RM, Kapur S, Howes OD, Stone JM, McGuire PK (2014). Antipsychotic treatment resistance in schizophrenia associated with elevated glutamate levels but normal dopamine function. Biological Psychiatry 75, e11-e13.

Demjaha A, Morgan K, Morgan C, Landau S, Dean K, Reichenberg A, Sham P, Fearon P, Hutchinson G, Jones PB, Murray RM, Dazzan P (2009). Combining dimensional and categorical representation of psychosis: the way forward for DSM-V and ICD-11? Psychological Medicine 39, 1943-1955.

Demjaha A, Murray RM, McGuire PK, Kapur S, Howes OD (2012). Dopamine synthesis capacity in patients with treatment-resistant schizophrenia. American Journal of Psychiatry 169, 1203-1210.

Dreher JC, Meyer-Lindenberg A, Kohn P, Berman KF (2008). Age-related changes in midbrain dopaminergic regulation of the human reward system. Proceedings of the National Academy of Sciences 105, 15106-15111.

Gallego JA, Robinson DG, Sevy SM, Napolitano B, McCormack J, Lesser ML, Kane JM (2011). Time to treatment response in first episode schizophrenia: should acute treatment trials last several months? Journal of Clinical Psychiatry 72, 1691.

Gardner DM, Murphy A, O'Donnell H, Centorrino F, Baldessarini RJ (2010). International consensus study of 
antipsychotic dosing. American Journal of Psychiatry 167, 686-693.

Harrell Jr. FE (2015). Regression Modeling Strategies: with Applications to Linear Models, Logistic and Ordinal Regression, and Survival Analysis, 2nd edn. Springer-Verlag: New York.

Harrison G, Hopper K, Craig T, Laska E, Siegel C, Wanderling J, Dube KC, Ganev K, Giel R, an der Heiden W, Holmberg SK, Janca A, Lee PW, León CA, Malhotra S, Marsella AJ, Nakane Y, Sartorius N, Shen Y, Skoda C, Thara R, Tsirkin SJ, Varma VK, Walsh D, Wiersma D (2001). Recovery from psychotic illness: a 15- and 25-year international follow-up study. British Journal of Psychiatry 178, 506-517.

Hastie T, Tibshirani R, Friedman J (2009). The Elements of Statistical Learning, 2nd edn. Springer: New York.

Howes OD, McCutcheon R, Agid O, de Bartolomeis A, van Beveren NJ, Birnbaum ML, Bloomfield MA, Bressan RA, Buchanan RW, Carpenter WT, Castle DJ, Citrome L, Daskalakis ZJ, Davidson M, Drake RJ, Dursun S, Ebdrup BH, Elkis H, Falkai P, Fleischacker WW, Gadelha A, Gaughran F, Glenthøj BY, Graff-Guerrero A, Hallak JE, Honer WG, Kennedy J, Kinon BJ, Lawrie SM, Lee J, Leweke FM, MacCabe JH, McNabb CB, Meltzer H, Möller HJ, Nakajima S, Pantelis C, Reis Marques T, Remington G, Rossell SL, Russell BR, Siu CO, Suzuki T, Sommer IE, Taylor D, Thomas N, Üçok A, Umbricht D, Walters JT, Kane J, Correll CU (2016). Treatment-resistant schizophrenia: Treatment Response and Resistance in Psychosis (TRRIP) working group consensus guidelines on diagnosis and terminology. American Journal of Psychiatry. doi:10.1176/appi.ajp.2016.16050503.

Kane J, Honigfeld G, Singer J, Meltzer H (1988). Clozapine for the treatment-resistant schizophrenic: a double-blind comparison with chlorpromazine. Archives of General Psychiatry 45, 789-796.

Kolakowska T, Williams A, Ardern M, Reveley M, Jambor K, Gelder M, Mandelbrote B (1985). Schizophrenia with good and poor outcome. I: early clinical features, response to neuroleptics and signs of organic dysfunction. British Journal of Psychiatry 146, 229-239.

Lally J, Ajnakina O, Di Forti M, Trotta A, Demjaha A, Kolliakou A, Mondelli V, Marques TR, Pariante C, Dazzan P, Shergil SS, Howes OD, David AS, MacCabe JH, Gaughran F, Murray RM (2016). Two distinct patterns of treatment resistance: clinical predictors of treatment resistance in first-episode schizophrenia spectrum psychoses. Psychological Medicine 46, 3231-3240.

Levine SZ, Rabinowitz J, Faries D, Lawson AH, Ascher-Svanum H (2012). Treatment response trajectories and antipsychotic medications: examination of up to 18 months of treatment in the CATIE chronic schizophrenia trial. Schizophrenia Research 137, 141-146.

Lieberman J, Jody D, Geisler S, Alvir J, Loebel A, Szymanski S, Woerner M, Borenstein M (1993). Time course and biologic correlates of treatment response in first-episode schizophrenia. Archives of General Psychiatry 50, 369-376.

Loebel AD, Lieberman JA, Alvir JM, Mayerhoff DI, Geisler SH, Szymanski SR (1992). Duration of psychosis and outcome in first-episode schizophrenia. American Journal of Psychiatry 149, 1183-1188.

MacMillan JF, Crow TJ, Johnson AL, Johnstone EC (1986). Short-term outcome in trial entrants and trial eligible patients. British Journal of Psychiatry 148, 128-133.

Marshall M, Lewis S, Lockwood A, Drake R, Jones P, Croudace $T$ (2005). Association between duration of untreated psychosis and outcome in cohorts of first-episode patients: a systematic review. Archives of General Psychiatry 62, 975-983.

McCreadie RG, Wiles D, Grant S, Crockett GT, Mahmood Z, Livingston MG, Watt JA, Greene JG, Kershaw PW, Todd NA (1989). The Scottish first episode schizophrenia study. VII. Two-year follow-up. Scottish Schizophrenia Research Group. Acta Psychiatrica Scandinavica 80, 597-602.

Meltzer HY (1997). Treatment-resistant schizophrenia - the role of clozapine. Current Medical Research and Opinion 14, $1-20$.

Meltzer HY, Rabinowitz J, Lee MA, Cola PA, Ranjan R, Findling RL, Thompson PA (1997). Age at onset and gender of schizophrenic patients in relation to neuroleptic resistance. American Journal of Psychiatry 154, 475-482.

Morgan C, Lappin J, Heslin M, Donoghue K, Lomas B, Reininghaus U, Onyejiaka A, Croudace T, Jones PB, Murray RM, Fearon P, Doody GA, Dazzan P (2014). Reappraising the long-term course and outcome of psychotic disorders: the AESOP-10 study. Psychological Medicine 44, 2713-2726.

National Institute for Health and Care Excellence (NICE) (2014). Psychosis and Schizophrenia in Adults: Treatment and Management (Clinical Guideline 178). Royal College of Psychiatrists: London.

Patel MX, Bishara D, Jayakumar S, Zalewska K, Shiers D, Crawford MJ, Cooper SJ (2014). Quality of prescribing for schizophrenia: evidence from a national audit in England and Wales. European Neuropsychopharmacology 24, 499-509.

R Core Team (2014). R: A Language and Environment for Statistical Computing. R Foundation for Statistical Computing: Vienna, Austria.

Robinson DG, Woerner MG, Alvir JM, Geisler S, Koreen A, Sheitman B, Chakos M, Mayerhoff D, Bilder R, Goldman R, Lieberman JA (1999). Predictors of treatment response from a first episode of schizophrenia or schizoaffective disorder. American Journal of Psychiatry 156, 544-549.

Schennach R, Riedel M, Musil R, Moller HJ (2012). Treatment response in first-episode schizophrenia. Clinical Psychopharmacology and Neuroscience 10, 78-87.

Sheitman B, Lieberman J (1998). The natural history and pathophysiology of treatment resistant schizophrenia. Journal of Psychiatric Research 32, 143-150.

Susser E, Finnerty M, Mojtabai R, Yale S, Conover S, Goetz R, Amador X (2000). Reliability of the life chart schedule for assessment of the long-term course of schizophrenia. Schizophrenia Research 42, 67-77.

World Health Organization (1992). The ICD-10 Classification of Mental and Behavioural Disorders: Clinical Descriptions and Diagnostic Guidelines. World Health Organization: Geneva.

World Health Organization (1994). Schedules for Clinical Assessment in Neuropsychiatry Version 2: Manual. World Health Organization, Division of Mental Health: Geneva. 